\title{
The Use of Scanning Electron Microscopy for the Analysis of Bacteriophage Binding to Acinetobacter baumanii
}

\author{
Brian M. Leroux ${ }^{1}$, Matthew Henry ${ }^{2}$, Biswajit Biswas ${ }^{2}$, and Robert K. Pope ${ }^{1}$ \\ 1. National Bioforensic Analysis Center, Fort Detrick, USA. \\ 2. Navy Medical Research Center, Biological Defense Research Division, Fort Detrick, USA.
}

Scanning Electron Microscopy (SEM) was used to ascertain the binding of bacteriophage (phage) to clinically relevant $A$. baumannii isolates. The use of phage for successful treatment of pathogenic bacterial infections in conjunction with antibiotics has been documented [1]. The current study examines bacteriophage samples from the US Navy phage library that were previously screened for the ability to inhibit the growth of $A$. baumannii. The phage (AB-Navy1, AB-Navy4, AB-Navy71, and ABNavy97 from the Myoviridae Family, and AbTP3Ф1 from the Podoviridae Family) were examined for their ability to bind to the surface of $A$. baumannii. These phage were used in conjunction with the three clinical isolates of $A$. baumannii TP1, TP2, and TP3 $[1,2]$. The clinical isolates were taken at different time points during the infection [1].

The objective of this study was to determine the binding of specific phage to different clinical isolates of A. baumannii. Figure 1 (A-C) demonstrates that the size, shape and surface texture of uninfected TP1, TP2 and TP3 were similar in appearance. While the concentration of each phage was similar upon infection, there is a large diversity in the number of phage seen bound to the surface of the bacteria. The binding of AB-Navy1 (D-F) and AB-Navy71 (M-O) is high for TP1, but becomes reduced for TP2 and selective for TP3. The binding levels for AB-Navy4 (G-I), AbTP3Ф1 (J-L) and AB-Navy97 (P-R) remain relatively consistent for $\mathrm{TP} 1, \mathrm{TP} 2$ and $\mathrm{TP} 3$. Although the binding remains consistent, previous data demonstrate that TP3 is resistant to lysis by AB-Navy4 and ABNavy97 [1]. The examination of the TP1 column shows that AB-Navy1, AB-Navy4, AB-Navy71, and AB-Navy97 (D, G, M, and P respectively) bound to TP1 with high efficiency. While the binding efficiency of AbTP3Ф1 was significantly lower, this specific phage was previously shown to cause the highest level of growth inhibition of TP1, TP2, and TP3 [2].

\section{References:}

[1] Schooley RT et al, Antimicrobial Agents and Chemotherapy 61(10) (2017), p. e00954. [2] All bacteria and phage were supplied by the Navy Medical Research Center, Biological Defense Research Division, 8300 Research Plaza, Fort Detrick, MD 21702. This work was funded under Agreement No. HSHQDC-07-C-00020 awarded by the Department of Homeland Security Science and Technology Directorate (DHS/S\&T) for the management and operation of the National Biodefense Analysis and Countermeasures Center (NBACC), a Federally Funded Research and Development Center. The views and conclusions contained in this document are those of the authors and should not be interpreted as necessarily representing the official policies, either expressed or implied, of the U.S. Department of Homeland Security. In no event shall the DHS, NBACC, or Battelle National Biodefense Institute (BNBI) have any responsibility or liability for any use, misuse, inability to use, or reliance upon the information contained herein. The Department of Homeland Security does not endorse any products or commercial services mentioned in this publication. 

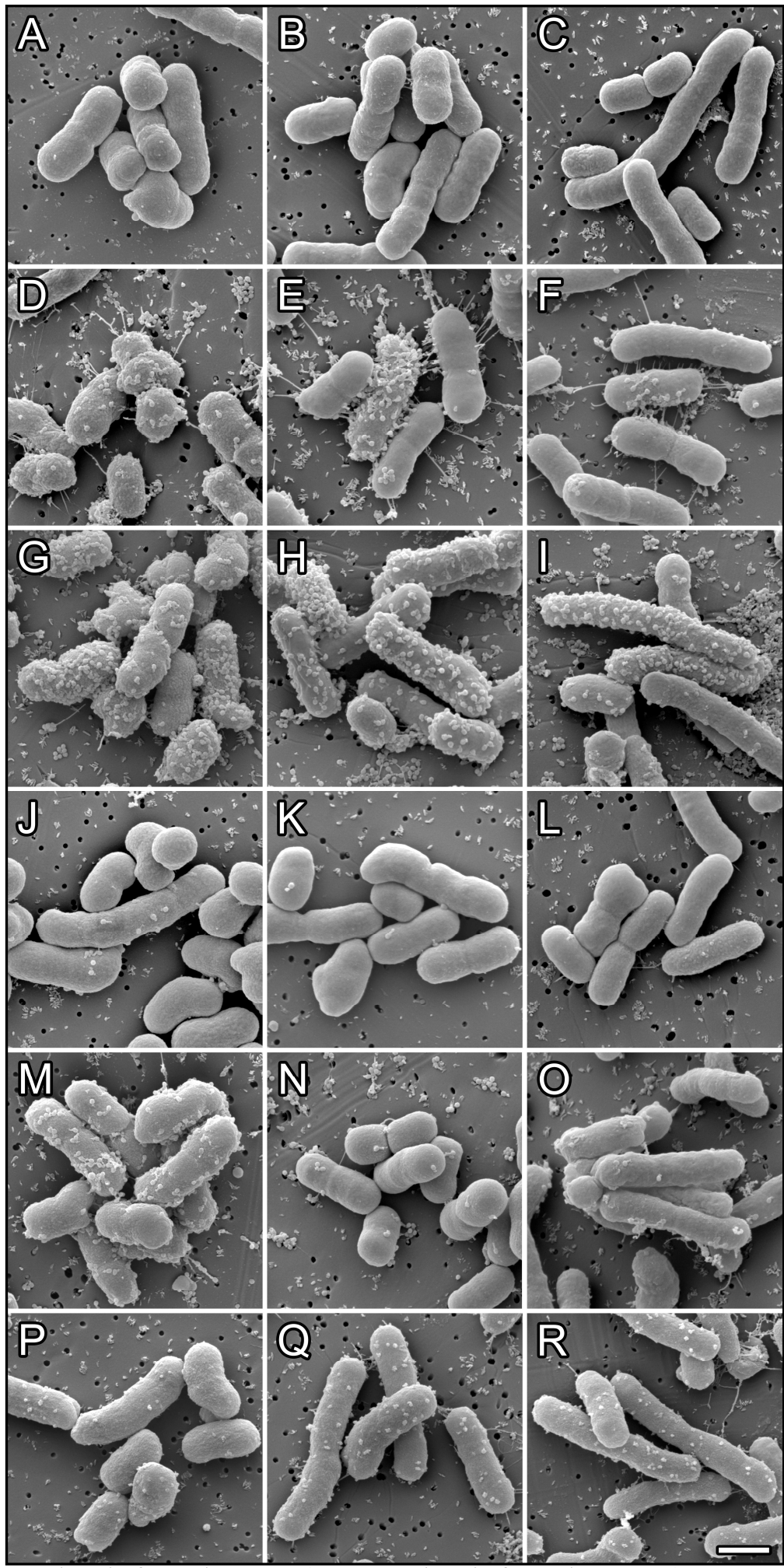

Figure 1. A)-Control uninfected TP1, B)-Control uninfected TP2, C)-Control uninfected TP3, D)-TP1 with AB-Navy1, E)-TP2 with AB-Navy1, F)-TP3 with AB-Navy1, G)-TP1 with AB-Navy4, H)-TP2 with AB-Navy4, I)-TP3 with AB-Navy4, J)-TP1 with AbTP3Ф1, K)-TP2 with AbTP3Ф1, L)-TP3 with AbTP3Ф1, M)-TP1 with AB-Navy71, N)-TP2 with AB-Navy71, O)-TP3 with AB-Navy71, P)-TP1 with AB-Navy97, Q)-TP2 with AB-Navy97, R)-TP3 with AB-Navy97. 